Research Article

\title{
Heat Transfer Potentiality and Flow Behavior in a Square Duct Fitted with Double-Inclined Baffles: A Numerical Analysis
}

\author{
Amnart Boonloi ${ }^{1}$ and Withada Jedsadaratanachai $\mathbb{i D}^{2}$ \\ ${ }^{1}$ Department of Mechanical Engineering Technology, College of Industrial Technology, King Mongkut's University of Technology \\ North Bangkok, Bangkok 10800, Thailand \\ ${ }^{2}$ Department of Mechanical Engineering, School of Engineering, King Mongkut's Institute of Technology Ladkrabang, \\ Bangkok 10520, Thailand
}

Correspondence should be addressed to Withada Jedsadaratanachai; withada.je@kmitl.ac.th

Received 2 April 2021; Revised 17 May 2021; Accepted 25 June 2021; Published 15 July 2021

Academic Editor: Parviz Ghadimi

Copyright (C) 2021 Amnart Boonloi and Withada Jedsadaratanachai. This is an open access article distributed under the Creative Commons Attribution License, which permits unrestricted use, distribution, and reproduction in any medium, provided the original work is properly cited.

\begin{abstract}
Numerical analysis of heat transfer mechanisms and flow topologies for the heat exchanger square channel (HESC) installed with the double-inclined baffles (DIB) is reported. The main objective of the present research is to study the influences of DIB height to duct height $(b / H=0.05-0.30)$, DIB distance to duct height $(P / H=1-1.5)$, and flow attack angle $\left(\alpha=30^{\circ}\right.$ and $\left.45^{\circ}\right)$ on the flow topologies, heat transfer features, and thermal performances. The Reynolds numbers (based on the entry HESC around 1002000) are analyzed for the present problem. The numerical models of the HESC installed with the DIB are solved with finite volume method (commercial code). The simulated results of the HESC installed with the DIB are reported in forms of flow topologies and heat transfer characteristics. The Nusselt numbers $(\mathrm{Nu})$, friction factors $(f)$, and thermal enhancement factors (TEF) of the HESC placed with the DIB are offered. As the numerical results, it is seen that the DIB produces the vortex streams and impinging streams in all cases. The vortex streams and impinging streams disturb the thermal boundary layer on the HESC walls that is a key motive for the growth of heat transfer rate. The best TEF of the HESC installed with the DIB is about 3.87 at $P / H=1, \alpha=30^{\circ}, \operatorname{Re}=2000$, and $b / H=0.15$. Additionally, the TEF contours, which help to design the HESC inserted with the DIB, are performed.
\end{abstract}

\section{Introduction}

Thermal development for production processes of many plants and engineering devices has been investigated by various research groups. The thermal development can be done by both passive and active techniques. The passive technique is an installation of turbulators or vortex generators in heat exchangers to produce vortex streams and impinging streams through heating/cooling sections. The vortex streams and impinging streams influence for a change of thermal boundary layer that is a main reason for heat transfer enhancement. Moreover, the vortex streams and impinging streams also grow fluid mixing power that is another cause for the heat transfer improvement. The flow features for different kinds of the vortex generators are not in similar patterns. Therefore, the vortex generator selection depends on applications of the heat exchangers. The active method is an addition of external power into heating/cooling processes to grow heat transfer rates. The active technique has great efficiency to extend heat transfer ability in the heat exchangers. However, the additional power brings higher production cost of the production processes. For the present investigation, the passive technique is picked to extend the heat transfer ability and thermal performance in the heat exchanger duct.

There are many works about the thermal improvement of various kinds for the heat exchangers with the passive method. The investigation methods can be separated into two ways: numerical and experimental studies. The experimental results from validated devices have high reliability and precision values. However, the experimental results could not explain the flow features and heat transfer patterns of the heat transfer processes in almost cases. The numerical 


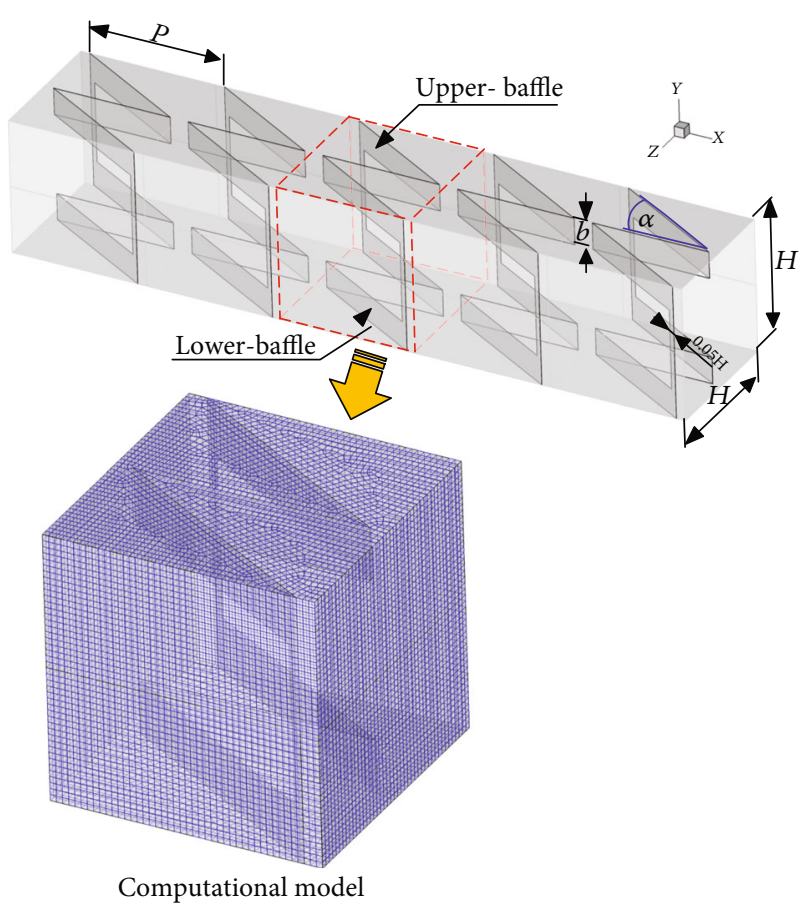

Figure 1: Physical model of the HESC installed with the DIB.

TABLE 1: Boundary conditions of the numerical model for the HESC inserted with the DIB.

\begin{tabular}{lc}
\hline Zone & Boundary condition \\
\hline Entry regime & Periodic boundary \\
Exit regime & Periodic boundary \\
HESC walls & Constant temperature of $310 \mathrm{~K}$ \\
DIB & Insulator/heat flux of $0 \mathrm{~W} / \mathrm{m}^{2}$ \\
\hline
\end{tabular}

investigation in the heat transfer processes is presented to explain the mechanisms in the tested sections. The knowledge on the flow features and heat transfer structures is important data to help to design the heat exchangers. However, numerical models must be validated to confirm reliance of the numerical results.

There are many published works about heat transfer and flow mechanisms, which are significant knowledge, for the heat exchangers and engineering devices [1-9]. The examples for the heat transfer improvement in various types of the heat exchangers with passive techniques of both numerical and experimental investigations are as follows. Bahiraei et al. [10] examined the growth of the heat transfer potentiality in a square section fitted with $\mathrm{V}$-shaped rib combining with nanofluid. The effects of the $45^{\circ} \mathrm{V}$-shaped rib on heat transfer potentiality, friction loss, and thermo-hydraulic performance were compared with those of the $60^{\circ} \mathrm{V}$-shaped rib. They presented that the lower entropy generation is found at the $45^{\circ} \mathrm{V}$-shaped rib. They also claimed that the larger rib height with smaller pitch spacing provides depressed exergy destruction and extends the higher second law efficiency. Bahiraei et al. [11] numerically investigated the thermo-

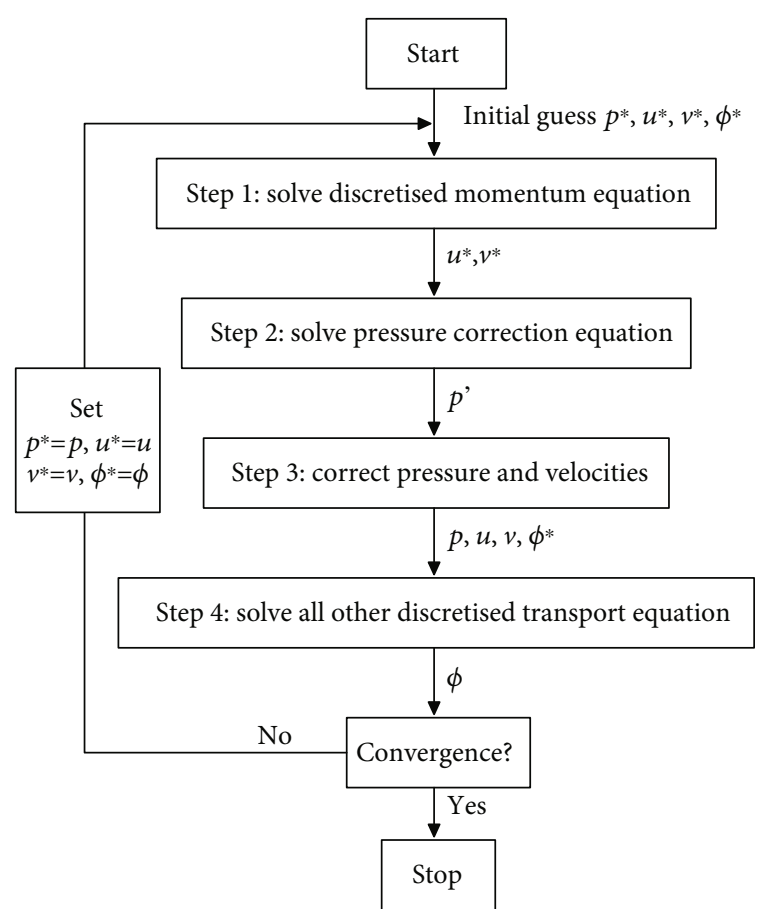

FIGURE 2: SIMPLE algorithm [22].

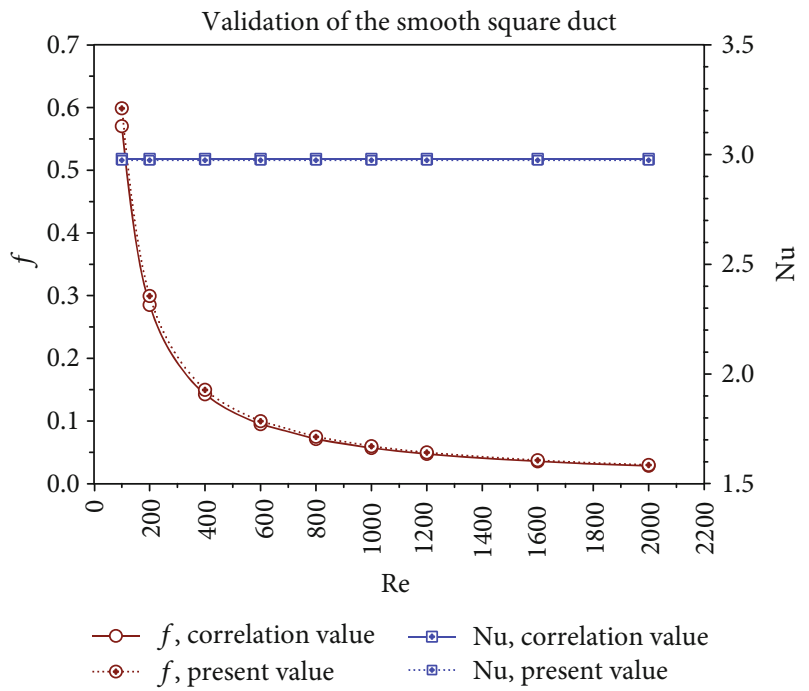

Figure 3: Validations on heat transfer and friction loss in the smooth duct without DIB.

hydraulic performance of $\mathrm{Cu}$-water nanofluid in a square duct installed with $90^{\circ} \mathrm{V}$-shaped rib. The influences of rib parameters (rib height and rib pitch) on heat transfer, thermal performance, and pressure loss were considered. They concluded that the heat transfer rate increases about $28.3 \%$ when augmenting the rib height from 2.5 to $7.5 \mathrm{~mm}$ at the pitch spacing of $50 \mathrm{~mm}$. A direct simulation of the entry region heat transfer for a channel (with an isothermal wall) fitted with ribs at $\operatorname{Re}=20460$ was reported by Matsubara et al. [12]. They found that the modification of thermal boundary layer affects for the enhancement of heat transfer coefficient at the entry regime of the ribbed channel. $\mathrm{Li}$ 


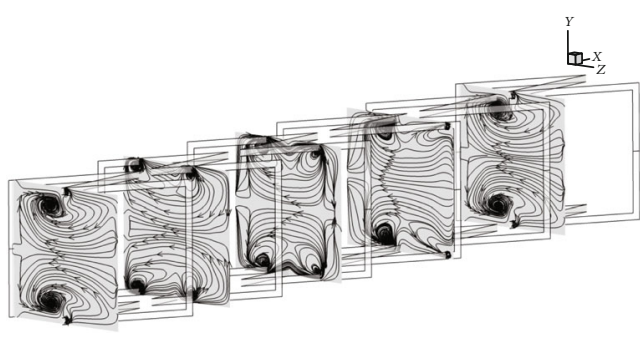

(a)

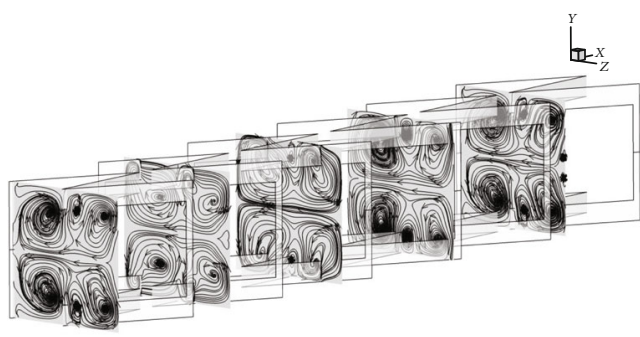

(c)

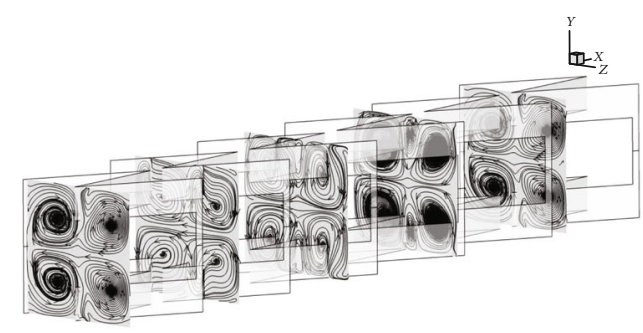

(e)

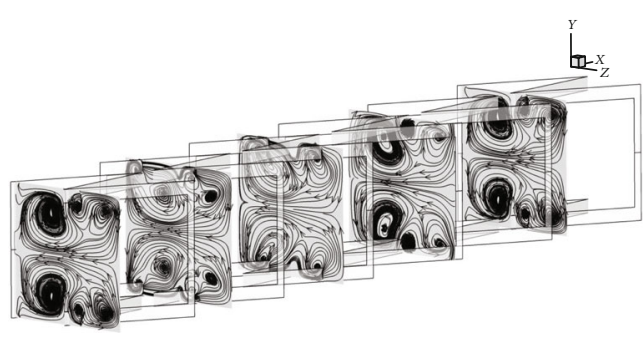

(b)

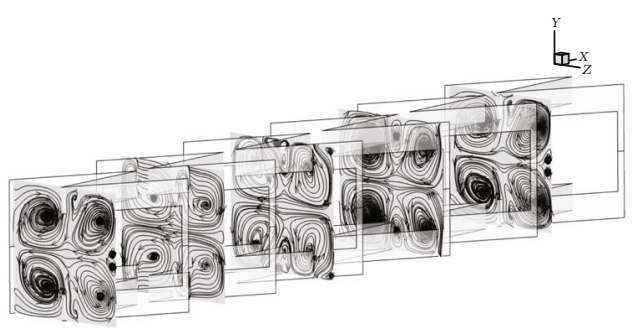

(d)

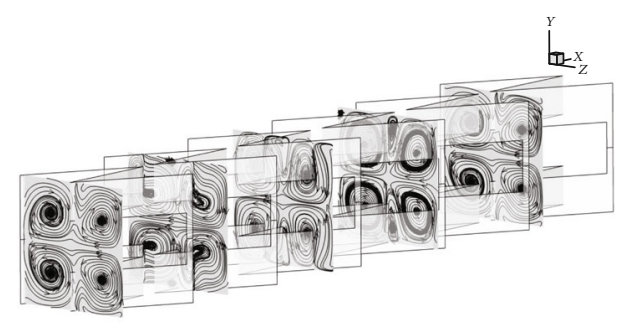

(f)

Figure 4: Streamlines in $y-z$ planes of the HESC installed with the DIB for (a) $b / H=0.05$, (b) $b / H=0.10,(\mathrm{c}) b / H=0.15$, (d) $b / H=0.20$, (e) $b / H=0.25$, and (f) $b / H=0.30$ at $\operatorname{Re}=800, \alpha=30^{\circ}$, and $P / H=1$.

et al. [13] studied the heat transfer potentiality and flow features in a microchannel with solid and porous ribs. They found that the thermal performance in the microchannel installed with the rib is greater than plain section with no rib. Bahiraei et al. [14] reported the second law analysis for nanofluid in a channel fitted with conical rib. The effects of rib arrangement and nanoparticle shape on flow configuration and heat transfer were considered. Jiang et al. [15] illustrated the two-phase flow and heat transfer profiles in a rectangular tested section with column-row-rib. Bai et al. [16] investigated the rib disturbed effect at the entry of a pin-fin array on pressure loss, thermal performance, and heat transfer ability for $\operatorname{Re}=7000-40000$. The influences of rib configurations $\left(60^{\circ} \mathrm{rib}, \mathrm{V}\right.$-shaped rib, and $\mathrm{W}$-shaped rib) on flow topology and heat transfer pattern were compared. They pointed out that the entry effect not only develops the heat transfer potentiality but also relieves the pressure loss that is a reason for the thermal performance increment. $\mathrm{Li}$ et al. [17] studied the pressure drop, heat transfer potentiality in a channel with miniature structured rib on one wall for $\mathrm{Re}=10000-60000$ (turbulent regime) by both numerical and experimental investigations. Their results revealed that the averaged Nusselt number and overall Nusselt number are greater than those of the smooth channel with no rib around 2.2-2.6 and 2.9-3.3 times, respectively. Bai et al. [18] simulated the pressure loss and heat transfer ability in a pin-fin array installed with rib turbulators. They summarized that the rib induces the secondary flow that is a reason for the heat transfer augmentation. They also informed that the $90^{\circ} \mathrm{rib}$ lets the best overall performance. The forced convective heat transfer and pressure loss of a square section with discrete combined baffle was reported by Boonloi and Jedsadaratanachai [19]. The impacts of flow directions and baffled heights on thermal performance in the square channel were considered for $\operatorname{Re}=5000-20000$. They found that the heat transfer ability of the square channel equipped with the discrete combined baffle is greater than the plain channel with no baffle around 2.8-6.0 times.

For the present investigation, heat transfer mechanisms and flow features in the heat exchanger square channel (HESC) installed with the double inclined baffles (DIB) are presented numerically. The effects of DIB height, DIB distance, and flow attack angle on the flow streams and heat transfer features are considered for laminar flow. The DIB is designed with the main aim to produce corotating flows. The corotating flows are compared with counter-rotating flows, which are produced by $\mathrm{V}$-shaped vortex generators $[9,19]$. The corotating flows may give a higher heat transfer rate with a lower pressure loss when comparing with the counter-rotating flows. The thermal performance assessments in the HESC equipped with the DIB are also reported. The TEF contours, which help to select the DIB parameters, 


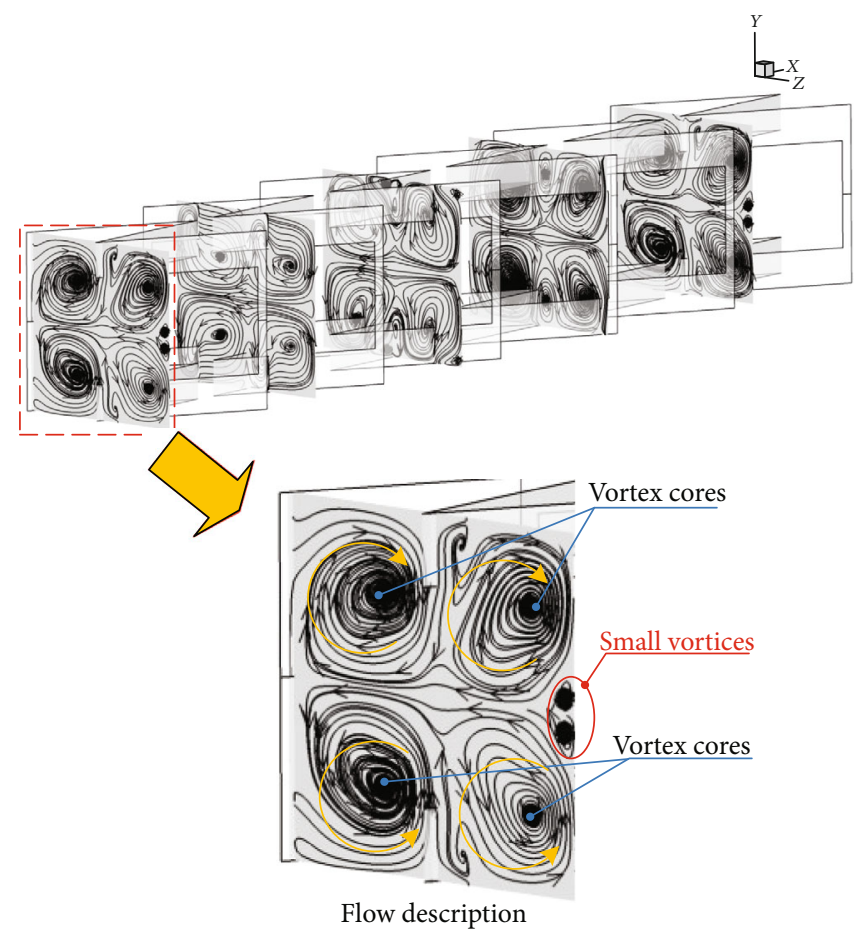

Figure 5: Flow description.

for the HESC with different $b / H$ and $P / H$ of the DIB are plotted.

\section{Physical Domain of the HESC Fitted with the DIB}

The HESC fitted with the DIB and computational model are illustrated as Figure 1. The DIB is designed similarly as an orifice due to the consideration about the installation, stability, and maintenance. The HESC height, $H=0.05 \mathrm{~m}$, is opted for the present work. The hydraulic diameter of the HESC, $D_{h}$, is equal to $H, D_{h}=H$. The DIB height is presented with " $b$ ". The DIB height to the duct height, $b / H$, is varied, $b / H$ $=0.05,0.10,0.15,0.20,0.25$, and 0.30 . The distance between the DIB or pitch spacing is presented with " $P$ ". The pitch spacing to the duct height, $P / H$, is varied, $P / H=1,1.25$, and 1.5. The flow attack angles of the DIB, $\alpha=30^{\circ}$ and $45^{\circ}$, are selected for the present investigation. The baffle thickness at the left-right sidewalls is about $0.05 \mathrm{H}$ for all cases.

\section{Mathematical Foundation and Initial and Boundary Conditions}

The methodology of the present work is referred from Reference [20]. The fluid flow and heat transfer in the HESC are assumed to be steady in three dimensions. The tested fluid, air (Prandtl number about 0.707 at $300 \mathrm{~K}$ ), is defined as incompressible flow. The Reynolds number based on the hydraulic diameter of about 100-2000 (laminar flow) is regarded for the present work. The thermal properties of the air are known to be constant at average bulk mean temperature. Considering at heat transfer mode, the forced con- vective heat transfer in the HESC is measured, while the other modes (radiation and natural convection) are ignored. Body force and viscous dissipation of the HESC is also neglected. No slip wall condition is applied for all HESC surfaces and DIB.

The Reynolds number can be determined as Equation (1).

$$
\operatorname{Re}=\frac{\rho \bar{u} D_{h}}{\mu} .
$$

The friction factor, $f$, in the HESC is calculated as Equation (2).

$$
f=\frac{(\Delta p / L) D_{h}}{1 / 2 \rho \bar{u}^{2}}
$$

The heat transfer ability in the HESC inserted with the DIB is presented with the local Nusselt number and average Nusselt number as Equations (3) and (4), respectively.

$$
\begin{gathered}
\mathrm{Nu}_{x}=\frac{h_{x} D_{h}}{k}, \\
\mathrm{Nu}=\frac{1}{A} \int \mathrm{Nu}_{x} \partial A .
\end{gathered}
$$

The thermal efficiency in the HESC inserted with the DIB is illustrated in form of thermal efficiency factor, TEF. The TEF is defined as the ratio of the heat transfer coefficient of an augmented surface, $h$, to that of a smooth surface, $h_{0}$, at a similar pumping power and given by the following: 


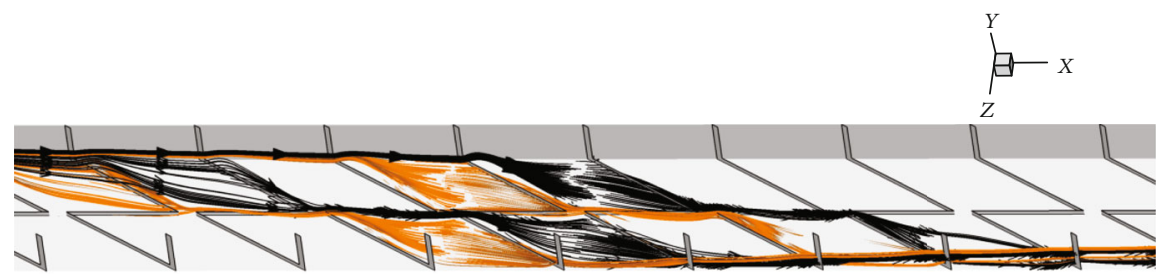

(a)

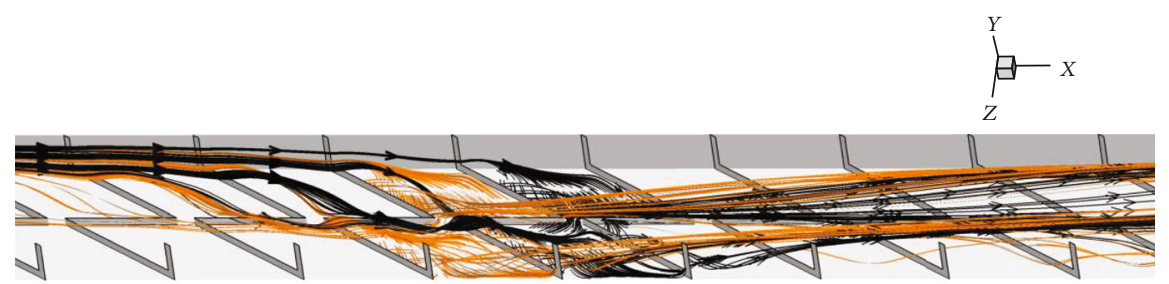

(b)

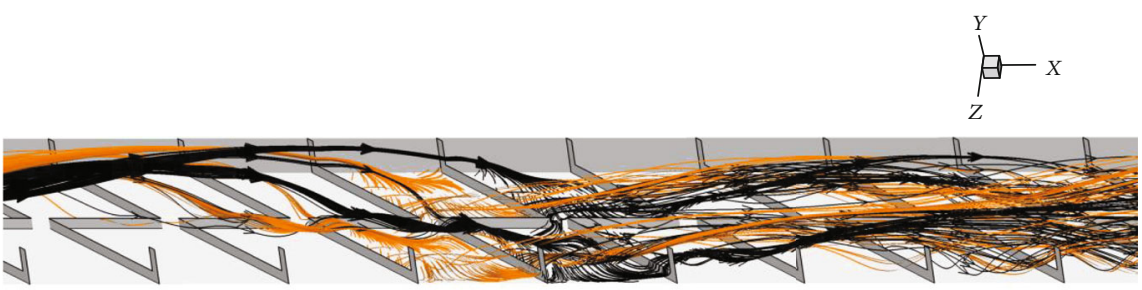

(c)

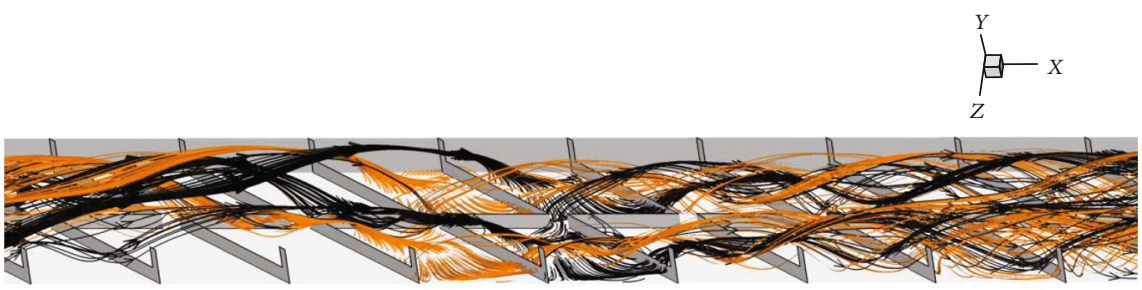

(d)

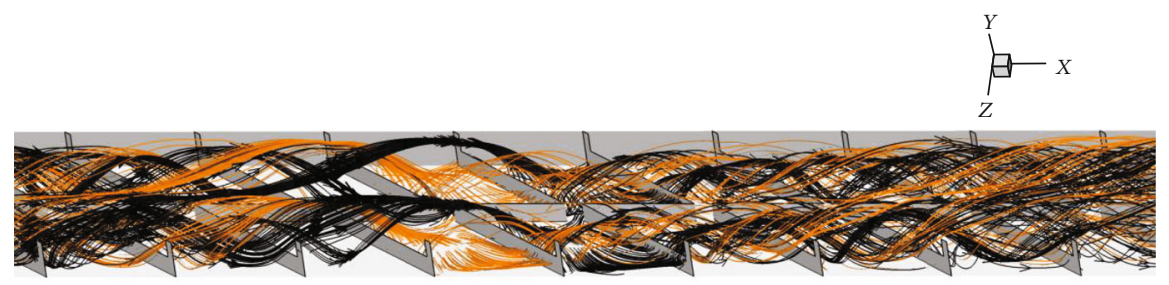

(e)

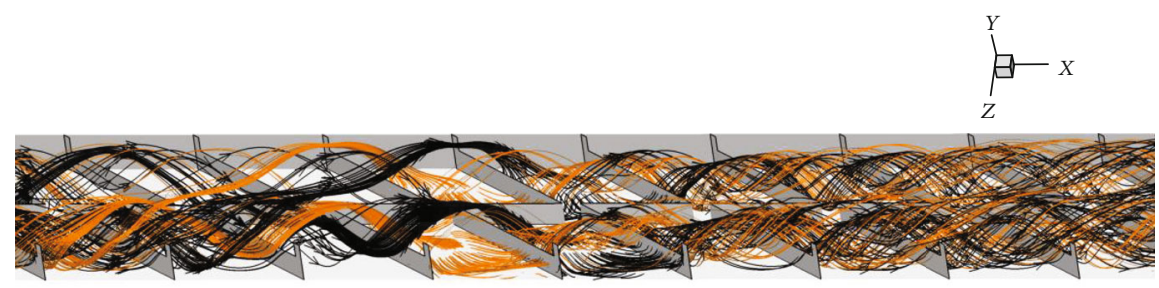

(f)

FIgURE 6: Longitudinal streams of the HESC installed with the DIB for (a) $b / H=0.05$, (b) $b / H=0.10$, (c) $b / H=0.15$, (d) $b / H=0.20$, (e) $b$ $/ H=0.25$, and (f) $b / H=0.30$ at $\operatorname{Re}=800, \alpha=30^{\circ}$, and $P / H=1$. 


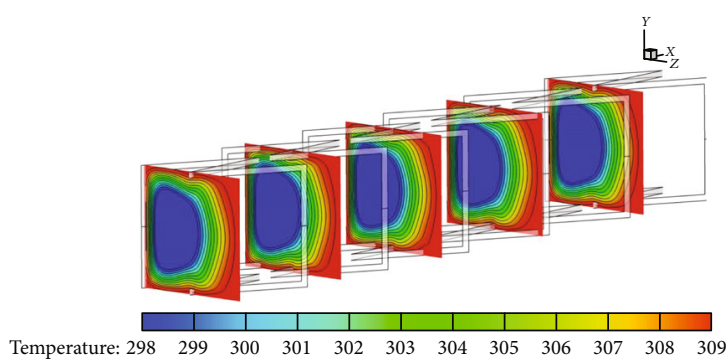

(a)

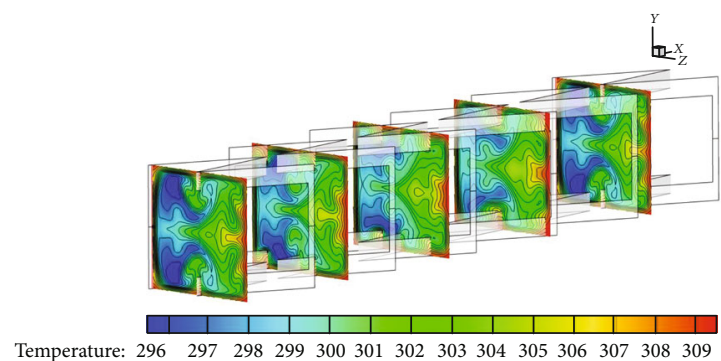

(c)

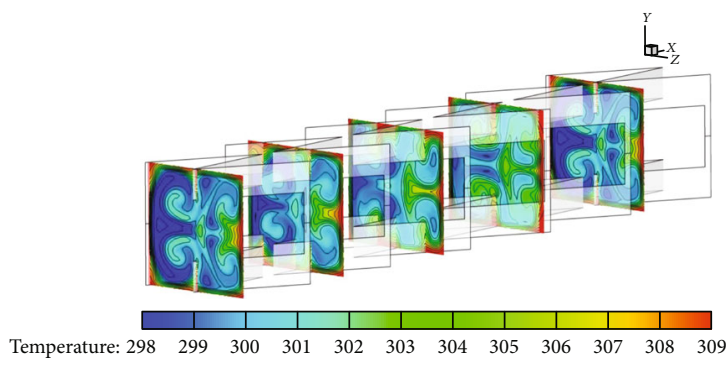

(e)

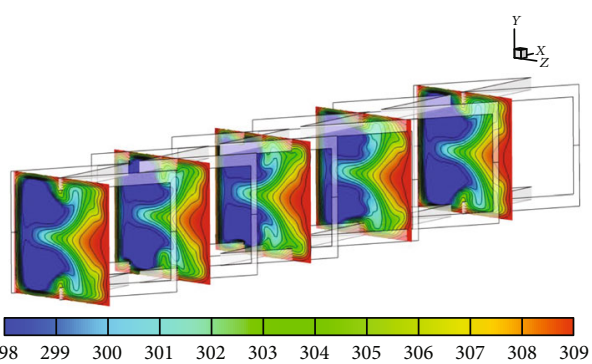

(b)

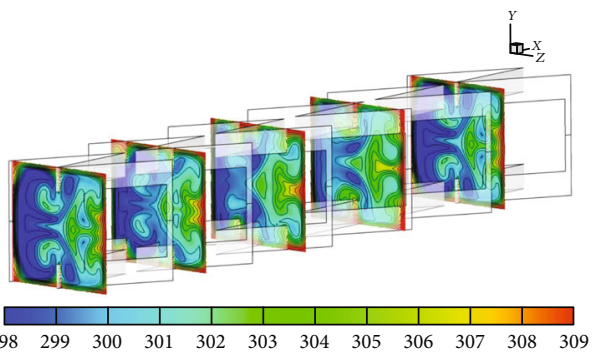

(d)

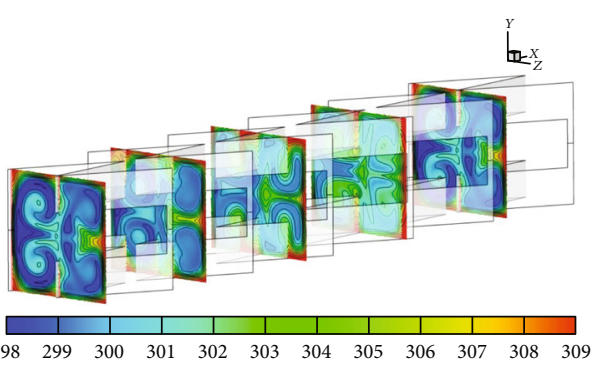

(f)

FIGURE 7: Fluid temperature contours in $y$ - $z$ planes of the HESC installed with the DIB for (a) $b / H=0.05,(b) b / H=0.10,(\mathrm{c}) b / H=0.15$, (d) $b / H=0.20$, (e) $b / H=0.25$, and (f) $b / H=0.30$ at $\mathrm{Re}=800, \alpha=30^{\circ}$, and $P / H=1$.

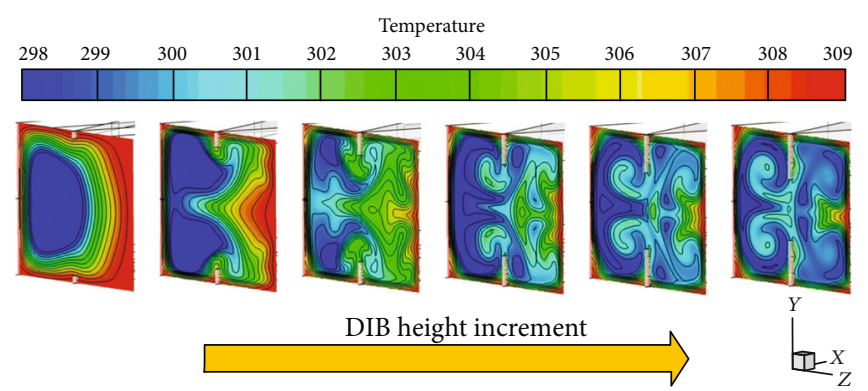

Figure 8: The change of the fluid temperature (or the change of the thermal boundary layer) in the HESC installed with the DIB at various DIB heights.

$$
\mathrm{TEF}=\left.\frac{h}{h_{0}}\right|_{p p}=\left.\frac{\mathrm{Nu}}{\mathrm{Nu}_{0}}\right|_{p p}=\frac{\mathrm{Nu} / \mathrm{Nu}_{0}}{\left(f / f_{0}\right)^{1 / 3}},
$$

where $\mathrm{Nu}_{0}$ and $f_{0}$ stand for Nusselt number and friction factor for the smooth duct, respectively.

The boundary conditions for the present work can be summarized as Table 1.

\section{Numerical Method}

The finite volume method with SIMPLE algorithm (as depicted in Figure 2) is opted to solve the numerical problem for the HESC inserted with the DIB. Based on the assumptions, the flow in the HESC is governed by the continuity, the Navier-Stokes, and the energy equations. The continuity equation, the momentum equation, and the energy equation 
are discretized by the power law scheme, power law scheme, and QUICK scheme, respectively. In the numerical process, the solutions are considered to be converged when the normalized residual values are less than $10^{-5}$ for all variables, but less than $10^{-9}$ only for the energy equation.

\section{Numerical Validation}

For the laminar flow, there are two parts in the numerical validation: (1) verification of the smooth HESC without DIB and (2) optimum grid cell or grid independence. The verification of the plain duct without DIB is done of both heat transfer and pressure loss. The comparisons between the present results with the values from the correlations [21] on Nusselt number and friction factor are done and depicted in Figure 3. As the figure, it is detected that the absolute average deviations of the Nusselt number are around 2\%, while around $3.2 \%$ for the friction factor.

For the grid test, the different grid cells (120000, 240000, 360000 , and 480000 cells) for the HESC inserted with the DIB $\left(b / H=0.15, P / H=1\right.$, and $\left.\alpha=30^{\circ}\right)$ are compared both Nusselt number and friction factor. It is seen that the growth of the cells from 120000 to 240000 has no impact for both the heat transfer and pressure loss in the HESC installed with the DIB. Thus, the grid around 120000 cells is picked for all investigated tests of the current research. As the validated results, it can be summarized that the numerical model has high reliability to predict flow topologies and heat transfer features of the HESC installed with the DIB.

\section{Numerical Result}

6.1. Flow and Heat Transfer Features in the HESC Fitted with the DIB. The flow topologies in the HESC equipped with the DIB are presented by considering the streamlines in transverse planes and longitudinal vortex flows. The streamlines in transverse planes are an indicator to check the flow patterns in the HESC, while the longitudinal vortex flows are a guide to view the impinging flows on the duct walls. The heat transfer mechanisms in the HESC equipped with the DIB are reported by regarding the temperature and local Nusselt number contours. The temperature contours are an indicator to check the variations of thermal boundary layer near the duct wall, while the local Nusselt number contours indicate the variations of the heat transfer mechanisms on the duct wall.

6.1.1. Influence of the DIB Height. Figures 4(a)-4(f) present the streamlines in $y-z$ planes in the HESC placed with the DIB for $b / H=0.05,0.10,0.15,0.20,0.25$, and 0.30 , respectively, at $\operatorname{Re}=800, \alpha=30^{\circ}$, and $P / H=1$. As seen in the figures, the creations of the vortex streams are seen for all $b / H$ values. The flow structure in the HESC is similarly found for all DIB heights. The DIB generates corotating flows at the upper-lower zones of the planes. The symmetry flow at the upper and lower parts of the planes is due to the symmetry structure of the DIB. The vortex flows consist of four major vortex cores. The vortex core position changes when changing the $b / H$ value. The vortex streams are a benefit phenomenon for the heat transfer and thermal performance

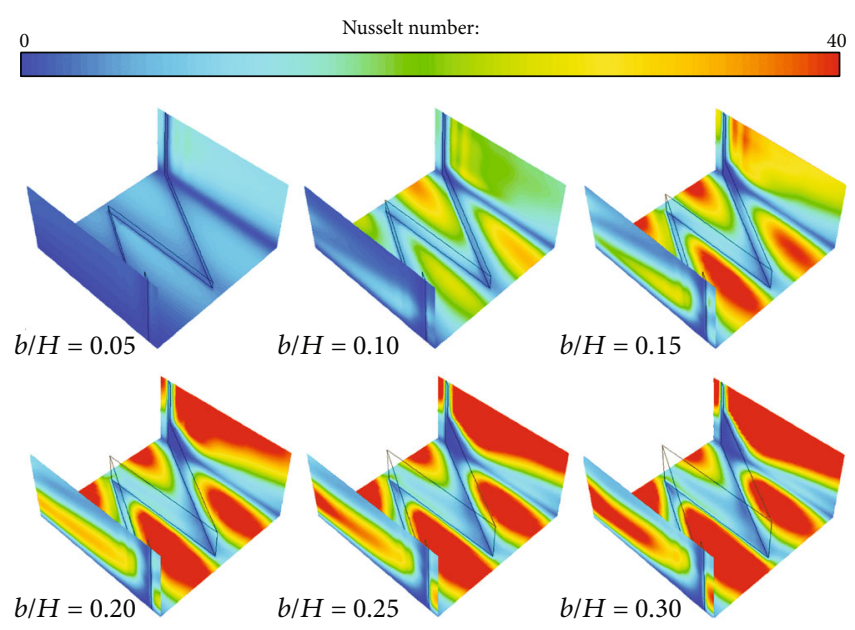

FIgURE 9: Local Nusselt number of the HESC installed with the DIB for various $b / H$ values at $\operatorname{Re}=800, \alpha=30^{\circ}$, and $P / H=1$.

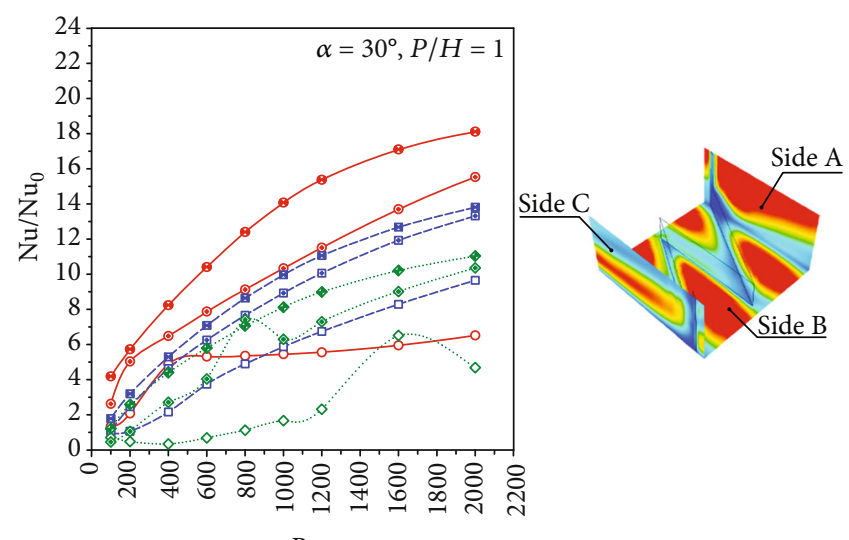

$\operatorname{Re}$

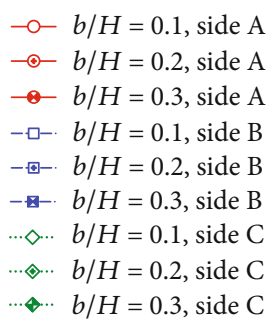

Figure 10: The comparison of the Nusselt number ratio with various duct sides.

improvements. The vortex streams would interrupt the thermal boundary layer on the HESC surfaces. The thermal boundary layer disruption is an important factor for the heat transfer increment. Moreover, the vortex streams help a better fluid blend in the HESC that is another cause for the heat transfer augmentation. The flow feature description in the HESC installed with the DIB is depicted as Figure 5.

The longitudinal vortex streams in the HESC placed with the DIB are presented as Figures 6(a)-6(f) for $b / H=0.05$, $0.10,0.15,0.20,0.25$, and 0.30 , respectively, at $\operatorname{Re}=800, \alpha=$ $30^{\circ}$, and $P / H=1$. As the figures, it is observed that the vortex streams impinge on the HESC walls for all cases. The power of the vortex streams seems to be stronger when increasing 


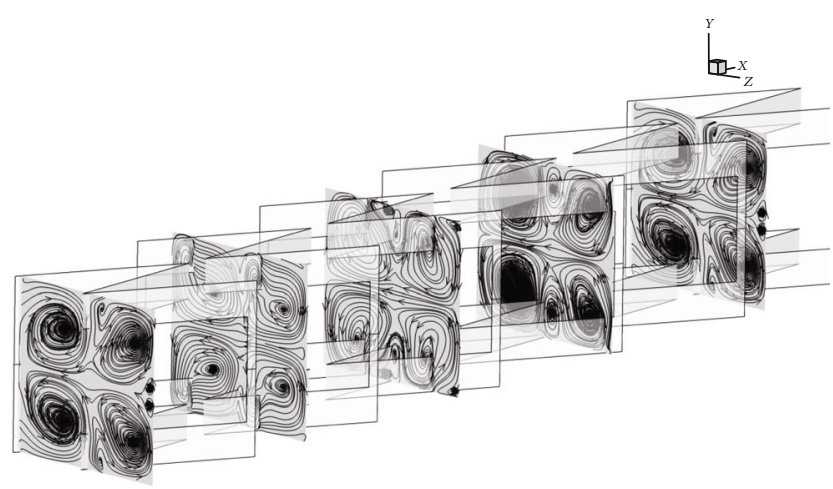

(a)

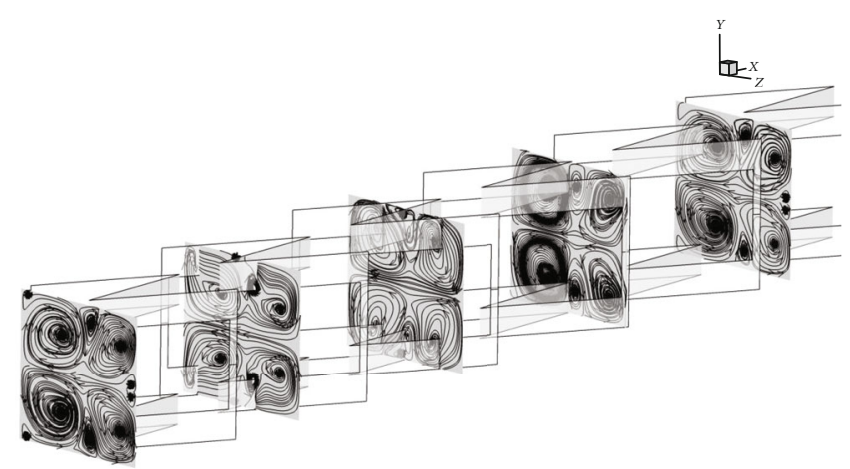

(b)

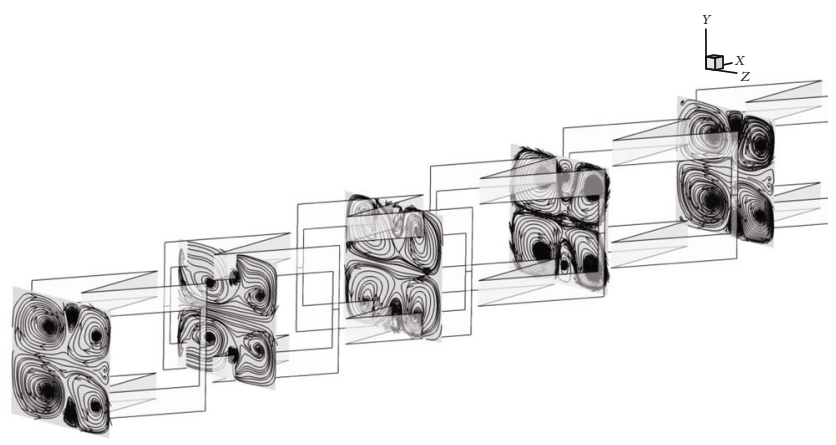

(c)

Figure 11: Streamlines in $y-z$ planes of the HESC installed with the DIB for (a) $P / H=1$, (b) $P / H=1.25$, and (c) $P / H=1.5$ at Re $=1000$, $\alpha=30^{\circ}$, and $b / H=0.2$.

the DIB height. Therefore, $b / H=0.30$ provides the strongest vortex stream, while $b / H=0.05$ performs the opposite result. In addition, the helical pitch length of the vortex streams decreases when rising the $b / H$ value. The decreased helical pitch brings higher vortex strength that is a cause for the heat transfer augmentation. The similar flow pattern in the HESC placed with the DIB is found for both flow attack angles.

The fluid temperature contours in the HESC inserted with the DIB in $y-z$ planes for $b / H=0.05,0.10,0.15,0.20$, 0.25 , and 0.30 are shown as Figures $7(\mathrm{a})-7(\mathrm{f})$, respectively, at $\operatorname{Re}=800, \alpha=30^{\circ}$, and $P / H=1$. The temperature contour of the HESC placed with the DIB is a guide to see the variation of the thermal boundary layer (see Figure 8). As seen in the figures, the vortex streams, which are created by the DIB, disrupt the thermal boundary layer on the HESC walls. When inserting the DIB in the HESC, the red layer thickness of the hot air near the HESC wall decreases, the blue layer of the cold fluid at the middle of the plane distributes to the HESC walls. The best distribution of the fluid temperature is detected when $b / H \geq 0.15$, while the poor distribution is detected at $b / H=0.05$. This is because the vortex strength directly affects for the fluid distribution and thermal boundary layer disturbance.

Figure 9 presents the local Nusselt number contours on the walls of the HESC placed with the DIB at different $b / H$ values for $\operatorname{Re}=800$ and $P / H=1$. Due to the similar flow configuration in the HESC, the heat transfer behavior is seen to be in a similar pattern. The peaks of the heat transfer rate in the HESC installed with the DIB are detected at the right side (side
A) and upper-lower side (side B) in all investigated cases. The heat transfer rate in the HESC inserted with the DIB enhances when augmenting the $b / H$ values due to the vortex strength increment. The similar heat transfer profile is found when changing the flow attack angles. The comparison of the average Nusselt number in the HESC installed with the DIB at various sidewalls is presented as Figure 10.

6.1.2. Influence of the DIB Distance. The streamlines in transverse planes in the HESC installed with the DIB are illustrated as Figures $11(\mathrm{a})-11(\mathrm{c})$, respectively, for $P / H=1,1.25$, and 1.5 at $\operatorname{Re}=1000, b / H=0.20$, and $\alpha=30^{\circ}$. As the figures, the vortex streams, which are created by the $\mathrm{DIB}$, are found in all planes of the studied cases. For all $\mathrm{P} /$ $H$ values, the flow profile contains four vortex cores. The vortex core positions in the HESC are in a similar place $(y / H$ and $z / H$ positions) when changing the $P / H$. This means that the $P / H$ has no affect for the variations of the vortex core position. The vortex strength decreases when increasing the $P /$ $H$ that impacts for the reduction of the heat transfer rate.

The temperature contours in $y-z$ planes in the HESC located with the DIB are plotted as Figures 12(a)-12(c) for $P / H=1,1.25$, and 1.5 , respectively, at $\mathrm{Re}=1000, b / H=0.20$ , and $\alpha=30^{\circ}$. As the figure, the temperature contours of the HESC are similarly seen when varying the $P / H$ (see Figure 13). The cold fluid spreads from the core of the HESC, while the hot fluid layer near the duct walls reduces. This means that the variations of the $P / H$ have slightly affect for the change of the heat transfer behavior. 


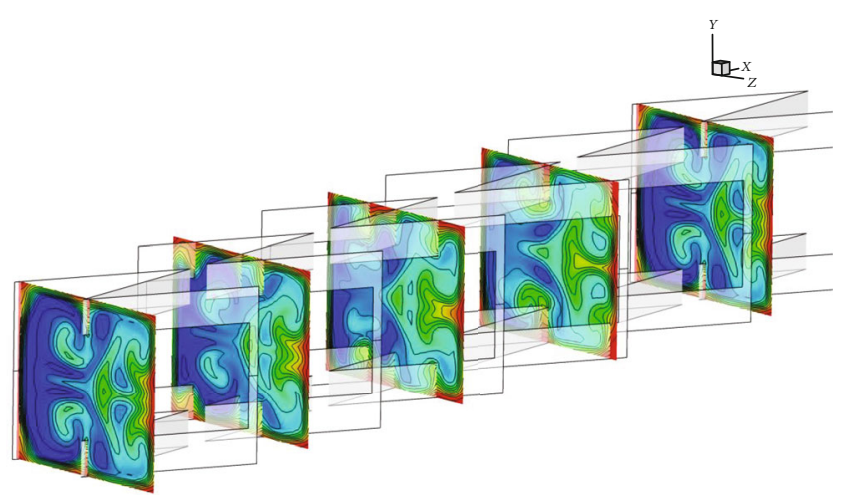

(a)

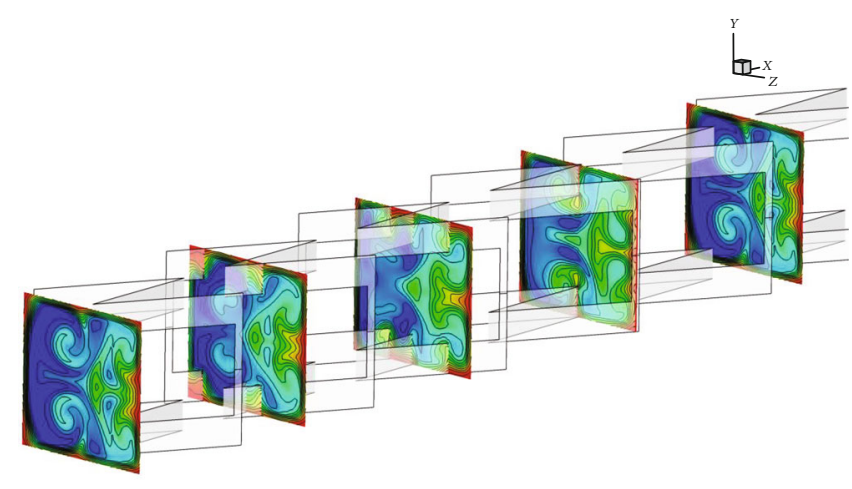

(b)

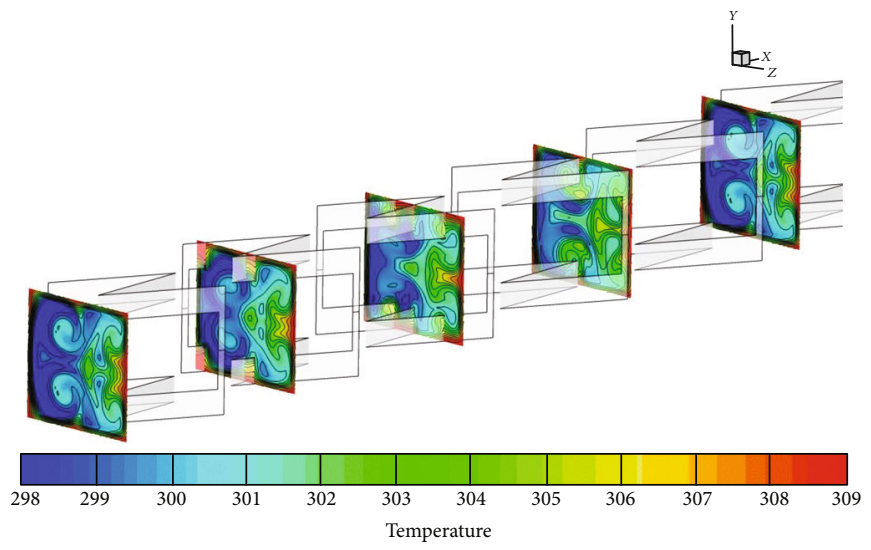

(c)

FIgURE 12: Fluid temperature contours in $y$ - $z$ planes of the HESC installed with the DIB for (a) $P / H=1,(b) P / H=1.25$, and (c) $P / H=1.5$ at $\operatorname{Re}=1000, \alpha=30^{\circ}$, and $b / H=0.2$.

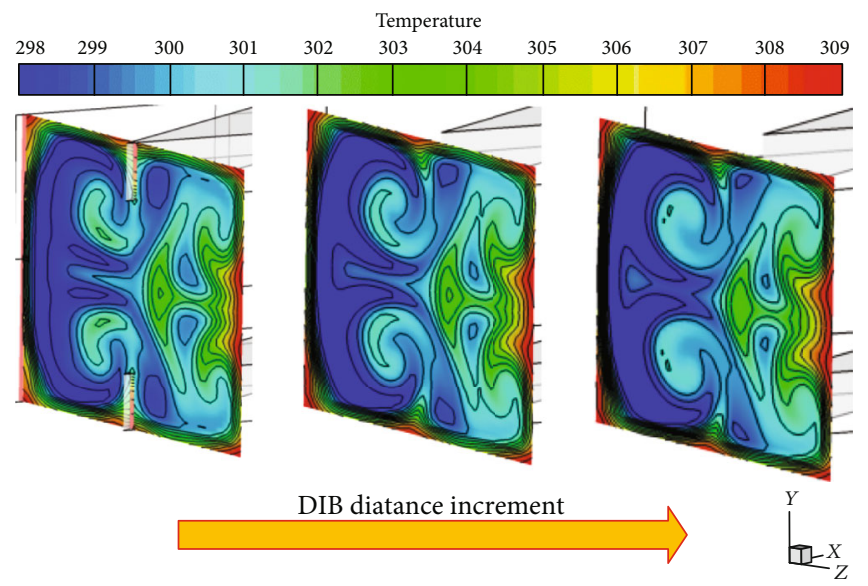

FIgURE 13: The change of the fluid temperature (or the change of the thermal boundary layer) in the HESC installed with the DIB at various DIB distances.

The local Nusselt number contours on the duct walls with various $P / H$ values of the HESC placed with the DIB are shown as Figure 14 at $\operatorname{Re}=1000, b / H=0.20$, and $\alpha=30^{\circ}$. The heat transfer profiles at various $P / H$ values are found to be very close. The peaks of the heat transfer ability are detected at the right and upper-lower sides of the duct walls in all $P / H$ cases. The Nusselt numbers on the duct walls slightly decrease when increasing $P / H$ due to the decressed vortex power.

6.2. Thermal Analysis in the HESC Installed with the DIB. The thermal analysis in the HESC inserted with the DIB can be separated into three sections: heat transfer, pressure loss, and thermal enhancement factor. The heat transfer rate in 


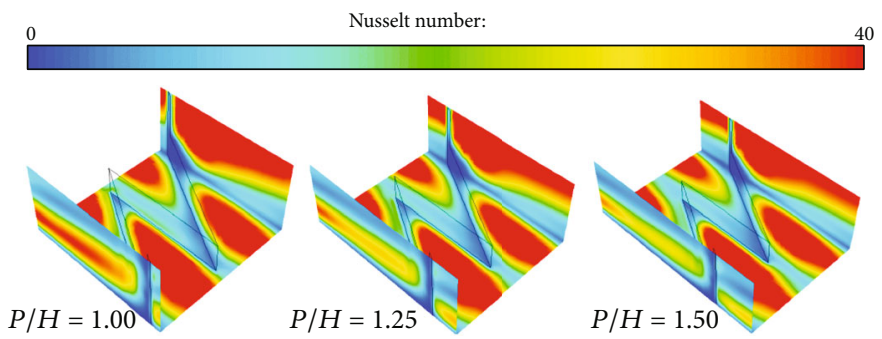

FIgURE 14: Local Nusselt number of the HESC installed with the DIB for various $P / H$ values at $\operatorname{Re}=1000, \alpha=30^{\circ}$, and $b / H=0.2$.

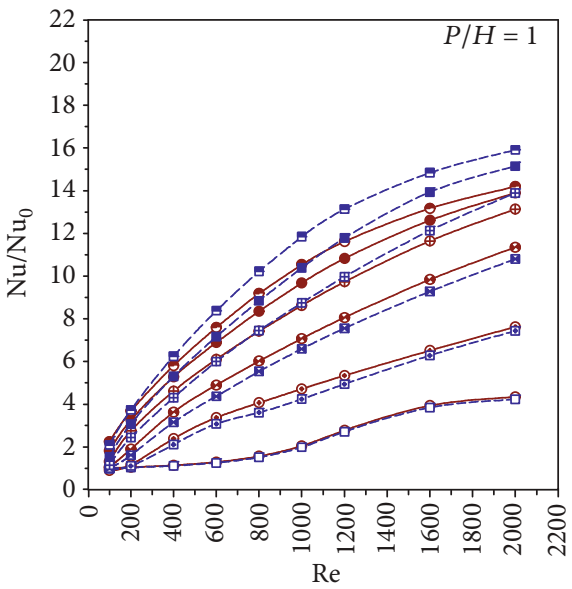

(a)

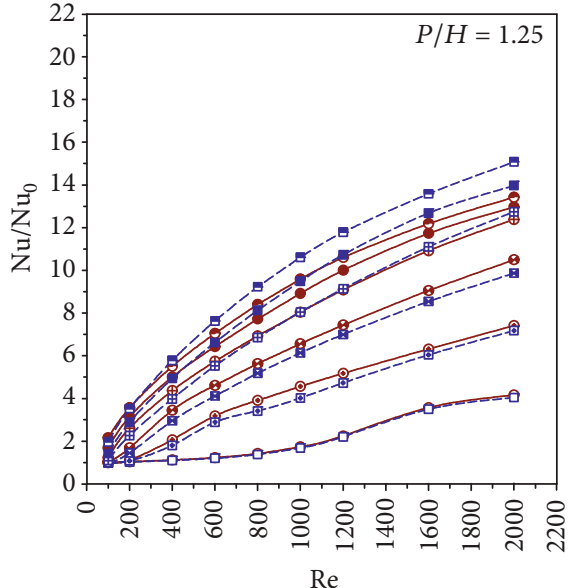

(b)

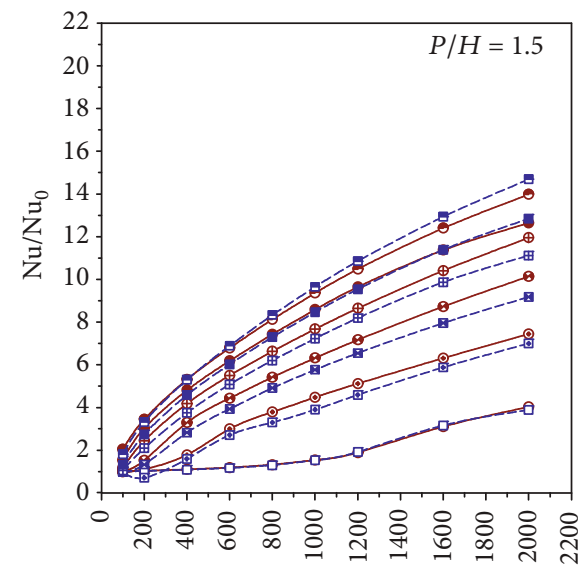

$\operatorname{Re}$

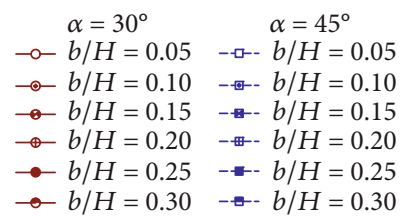

(c)

Figure 15: $\mathrm{Nu} / \mathrm{Nu}_{0}$ vs. Re in the HESC installed with the DIB for (a) $P / H=1$, (b) $P / H=1.25$, and (c) $P / H=1.5$.

the HESC equipped with the DIB is plotted as Nusselt number, while the pressure loss and efficiency are created as friction factor and thermal enhancement factor, respectively.
6.2.1. Heat Transfer Analysis. The variations of the $\mathrm{Nu} / \mathrm{Nu}_{0}$ with Reynolds number at different $b / H$ values in the HESC inserted with the DIB are plotted as Figures 15(a)-15(c) for 


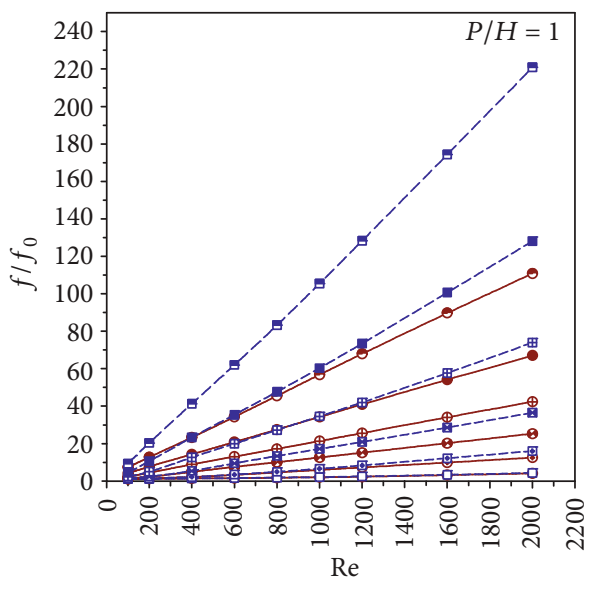

(a)

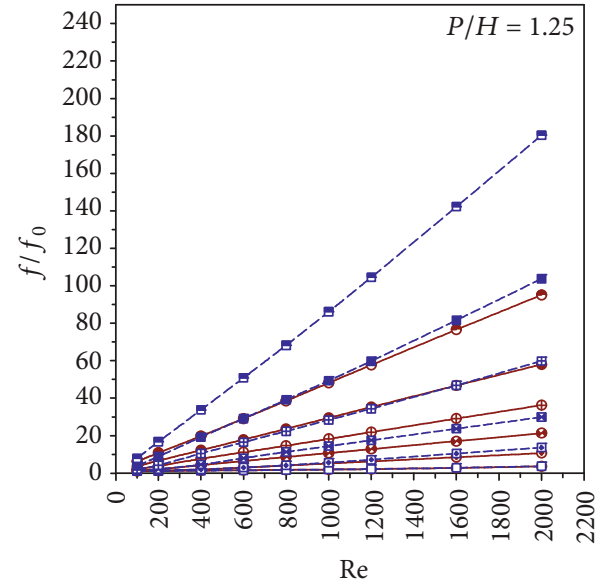

(b)

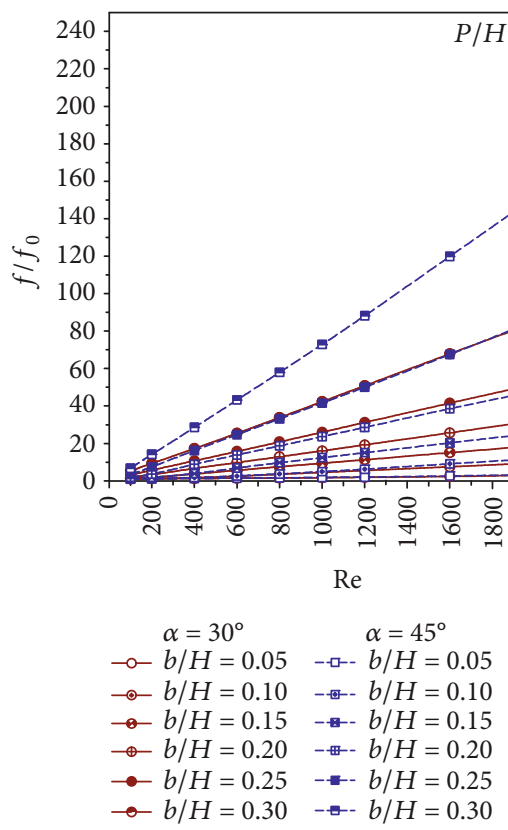

(c)

FIgure 16: $f / f_{0}$ vs. Re in the HESC installed with the DIB for (a) $P / H=1$, (b) $P / H=1.25$, and (c) $P / H=1.5$.

$P / H=1,1.25$, and 1.5 , respectively. In general, the heat transfer potentiality in the HESC placed with the DIB grows when rising the Reynolds number for all testes. This is because the increment of the Reynolds number brings higher vortex strength. At similar $b / H$, the $\mathrm{Re}=2000$ gives the highest heat transfer rate, while the $\mathrm{Re}=100$ performs the lowest heat transfer ability. The Nusselt number improves when rising the DIB height due to the increased vortex strength. At similar $P / H$ and flow attack angle, the $b / H=0.30$ provides the greatest heat transfer ability, while the $b / H=0.05$ gives the reversed result. The $P / H=1$ gives the greatest heat transfer potentiality for both flow attack angles. The heat transfer ability of the HESC at $P / H=1.25$ is found to be higher than the $P / H=1.5$ for the flow attack angle of $45^{\circ}$. For the flow attack angle of $30^{\circ}$, the Nusselt numbers of the HESC placed with the DIB at $P / H=1.25$ and 1.5 are very close. The flow attack angle of $45^{\circ}$ gives slightly higher Nusselt number than the flow attack angle of $30^{\circ}$ when $b / H>0.15,0.15$, and 0.20 , respectively, for $P / H=1,1.25$, and 1.5. The $P / H=1$ performs greater Nusselt number ratios than the $P / H=1.25$ and 1.5 within $7.58 \%$ and $10.66 \%$, respectively, for $\alpha=30^{\circ}$, while around $8.61 \%$ and $19.94 \%$, respectively, for $\alpha=45^{\circ}$.

At $\operatorname{Re}=2000$ and $\alpha=30^{\circ}$, the Nusselt number ratios are around $4.34,7.63,11.35,13.13,13.89$, and 14.19 , respectively, for $b / H=0.05,0.10,0.15,0.20,0.25$, and 0.30 , while around $4.17,7.41,10.49,12.38,12.97$, and 13.42 , respectively, for $P /$ $H=1.25$. The Nusselt numbers of the HESC with $P / H=1.5$ are greater than those of the smooth duct around 4.03, 7.44, $10.14,11.95,12.64$, and 13.98 times, respectively, when seeing at the highest Reynolds number. For $\alpha=45^{\circ}$, the highest Nusselt number ratios are around 15.91, 15.08, and 14.69, respectively, for $P / H=1,1.25$, and 1.5 .

6.2.2. Pressure Loss Analysis. The $f / f_{0}$ in the HESC placed with the DIB at various $b / H$, Reynolds numbers, and flow attack angles are plotted as Figures 16(a)-16(c), respectively, 


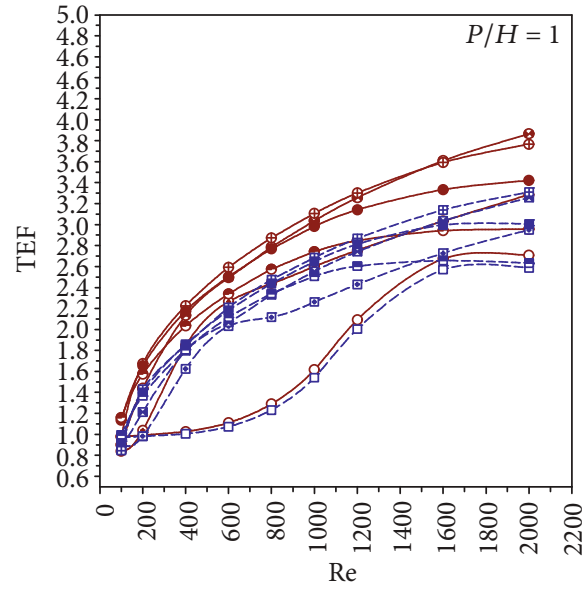

(a)

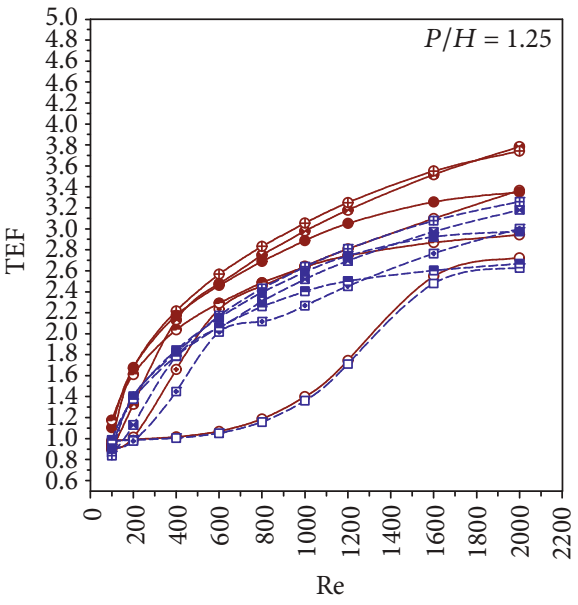

(b)

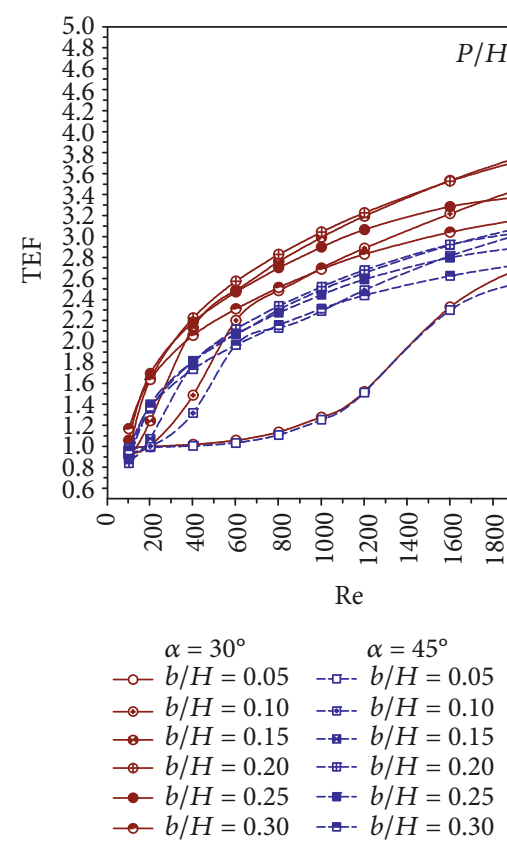

(c)

Figure 17: TEF vs. Re in the HESC installed with the DIB for (a) $P / H=1$, (b) $P / H=1.25$, and (c) $P / H=1.5$.

for $P / H=1,1.25$, and 1.5. Generally, $f / f_{0}$ in the HESC placed with the DIB significantly increase when increasing the Reynolds number and DIB height. At similar flow attack angle and $P / H$, the maximum $f / f_{0}$ is detected at $b / H=0.30$, while the opposite result is found at $b / H=0.05$. The increment of the $P / H$ values leads to the reduction of the friction loss. The tested section with $P / H=1$ provides higher friction loss than the $P / H=1.25$ and 1.5 within $15.79 \%$ and $25.42 \%$, respectively, for $\alpha=30^{\circ}$, while around $19.12 \%$ and $35.07 \%$, respectively, for $\alpha=45^{\circ}$. The flow attack angle of $45^{\circ}$ gives larger friction loss than the flow attack angle of $30^{\circ}$ in all $\mathrm{P} /$ $H$ values. The pressure loss in the tested section with the flow attack angle of $45^{\circ}$ is found to be higher than the flow attack angle of $30^{\circ}$ around $49.82 \%, 47.28 \%$, and $44.19 \%$, respectively, for $P / H=1,1.25$, and 1.5 , when considered at $\mathrm{Re}=$ 2000. The maximum friction factor ratios are around
$110.82,95.05$, and 84.66 for $P / H=1,1.25$, and 1.5 , respectively, of $\alpha=30^{\circ}$, while around 220.86, 180.36, and 151.68, respectively, for $\alpha=45^{\circ}$.

6.2.3. TEF Analysis. The relations of the TEF with Reynolds numbers at various $b / H$ and flow attack angles in the HESC installed with the DIB are depicted as Figures 17(a)-17(c) for $P / H=1,1.25$, and 1.5 , respectively. The thermal performance in the HESC inserted with the DIB is greater than the plain duct with no DIB for all investigated tests (TEF $>1$ ). As the figures, the TEF enhances when augmenting the Reynolds number. Due to the $b / H=0.05$ gives lowest vortex strength which directly affects for the heat transfer rate, thus the $b / H=0.05$ offers the lowest TEF for all $P / H$ values. The optimum TEF is found at $b / H=0.15$ for all $P /$ $H$ values of the flow attack angle of $30^{\circ}$, while observed at $b$ 

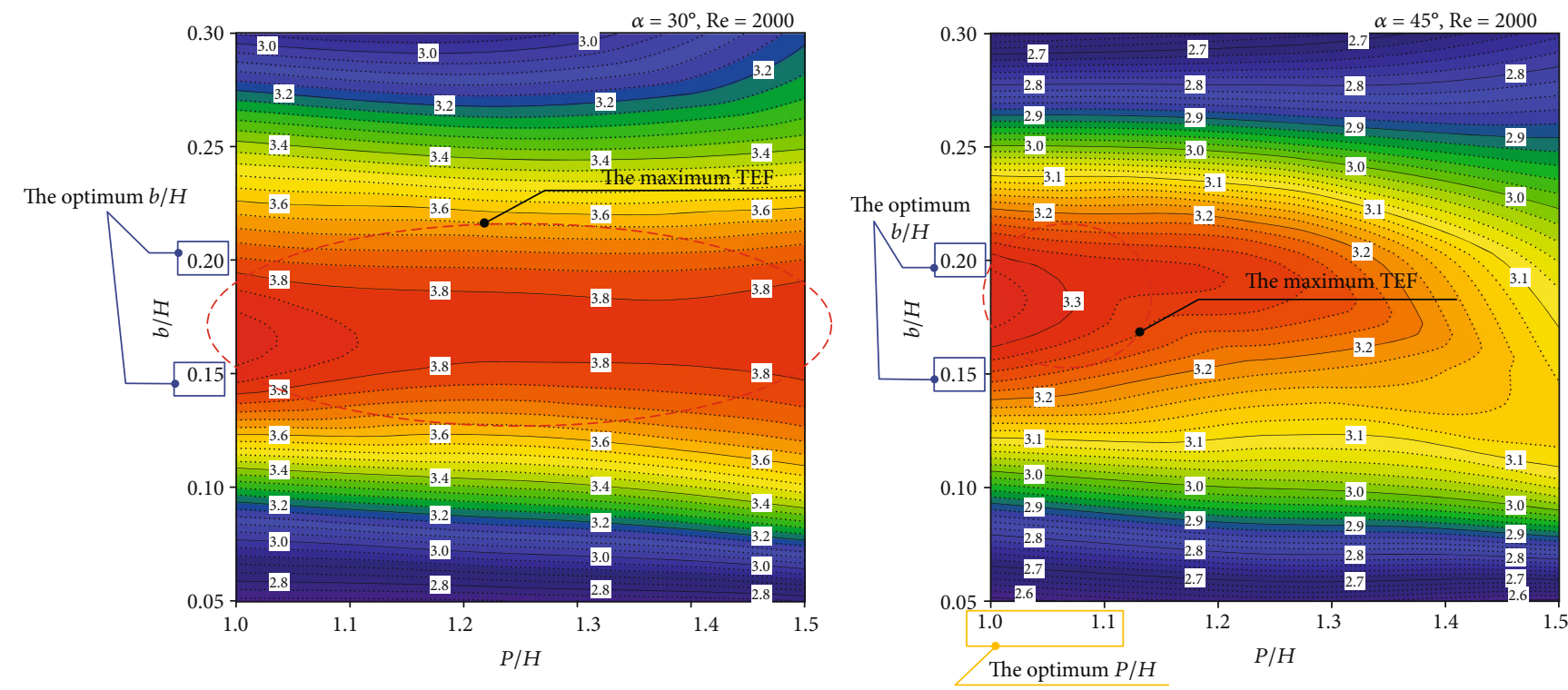

FIgURE 18: The TEF contours for both flow attack angles at $\mathrm{Re}=2000$ with different $P / H$ and $b / H$ values.

$/ H=0.20,0.20$, and 0.15 for the flow attack angle of $45^{\circ}$ at $P / H=1,1.25$, and 1.5 , respectively. Considering at $\mathrm{Re}=$ 2000 , the TEF is around $3.87,3.78$, and 3.81 for $P / H=1$, 1.25 , and 1.5 , respectively, for $\alpha=30^{\circ}$, while around 3.31 , 3.26 , and 3.12, respectively, for $\alpha=45^{\circ}$.

\section{Conclusion}

In this paper, the numerical analysis on heat transfer potentiality, pressure loss, and thermo-hydraulic performance in the HESC installed with the DIB is performed. The effects of flow attack angle, DIB height, DIB distance on flow, and heat transfer features are considered. As the simulated results, the main findings of the current investigation can be concluded as follows.

(i) The DIB creates vortex streams and impinging streams through the HESC for all investigated cases. The vortex streams and impinging streams are a disruptor of thermal boundary layer on the HESC surfaces. The disturbed thermal boundary layer is a significant key to improve the heat transfer potentiality. The vortex streams and impinging streams also help to enhance the power of a turbulent mixing. The improved fluid blending is another reason for the development of the heat transfer ability. The vortex power depends on the flow attack angle, DIB height, DIB distance, and Reynolds number. The vortex force increases when growing the DIB height and Reynolds number and with reducing the DIB distance

(ii) In comparison, the flow attack angle of $30^{\circ}$ operates nearly values of heat transfer ability with lower pressure loss when compared with the flow attack angle of $45^{\circ}$. Therefore, the thermal enhancement factor of the flow attack angle of $30^{\circ}$ is higher than the flow attack angle of $45^{\circ}$. The best thermal enhancement factor of the current work is around 3.87 at $\alpha=30^{\circ}$, $b / H=0.15$, and $P / H=1$. As the range investigates, the Nusselt number and friction factor values of the HESC installed with the DIB are upper than the plain duct without DIB around 1.00-15.91 and 1.00-220.86 times, respectively. The optimum TEF for both flow attack angles is found in the range of $b / H \approx 0.15-0.20$ and $P / H \approx 1$ as depicted in Figure 18

(iii) The peaks of heat transfer rate due to the impinging streams are obviously found at the side wall (side A) for all investigated cases. The knowledge about the impinging regime in the HESC is an advantage for some types of the heat exchangers such as solar air heaters, which require only one side for a heating surface

(iv) When considering about installation, the DIB is more stable vortex generator when compared with baffle, rib, or winglet, which are placed on the duct walls. The heat transfer rate, pressure loss, and thermal performance of the DIB and V-shaped vortex generators [9] are very close

\section{Abbreviations}

DIB: Double-inclined baffle

HESC: Heat exchanger square channel

TEF: Thermal efficiency factor $\left(=\left(\mathrm{Nu} / \mathrm{Nu}_{0}\right) /\left(f / f_{0}\right)^{1 / 3}\right)$.

\section{Symbols}

$b$ : DIB height $(\mathrm{m})$

$D_{h}$ : Hydraulic dimeter $(\mathrm{m})$

$f: \quad$ Friction factor

$H$ : HESC height 
$h$ : $\quad$ Convective heat transfer coefficient $\left(\mathrm{W} \mathrm{m}^{-2} \mathrm{~K}^{-1}\right)$

$k$ : Thermal conductivity $\left(\mathrm{W} \mathrm{m}^{-1} \mathrm{~K}^{-1}\right)$

$\mathrm{L}$ : Periodic length of the physical model (m)

Nu: Nusselt number $\left(=h D_{h} / k\right)$

$P: \quad$ Pitch distance $(\mathrm{m})$

$p$ : $\quad$ Static pressure $(\mathrm{Pa})$

Re: Reynolds number

T: $\quad$ Temperature $(\mathrm{K})$

$\bar{u}$ : $\quad$ Mean velocity in channel $\left(\mathrm{m} \mathrm{s}^{-1}\right)$.

\section{Greek Letters}

$\rho:$ Density $\left(\mathrm{kg} \mathrm{m}^{-3}\right)$

$\mu$ : Dynamic viscosity $\left(\mathrm{kg} \mathrm{m}^{-1} \mathrm{~s}^{-1}\right)$.

\section{Subscript}

0: $\quad$ Plain duct without DIB

$p p$ : Pumping power.

\section{Data Availability}

No data were used to support this study.

\section{Conflicts of Interest}

The authors declare that there is no conflict of interest regarding the publication of this article.

\section{Acknowledgments}

The authors would like to thank Assoc. Prof. Dr. Pongjet Promvonge for suggestions. This research was funded by King Mongkut's University of Technology North Bangkok.

\section{References}

[1] M. A. Alazwari and M. R. Safaei, "Combination effect of baffle arrangement and hybrid nanofluid on thermal performance of a shell and tube heat exchanger using 3-D homogeneous mixture model," Mathematics, vol. 9, no. 8, p. 881, 2021.

[2] F. Garoosi, M. R. Safaei, M. Dahari, and K. Hooman, "Eulerian-Lagrangian analysis of solid particle distribution in an internally heated and cooled air-filled cavity," Applied Mathematics and Computation, vol. 250, pp. 28-46, 2015.

[3] M. R. Safaei, A. Karimipour, A. Abdollahi, and T. K. Nguyen, "The investigation of thermal radiation and free convection heat transfer mechanisms of nanofluid inside a shallow cavity by lattice Boltzmann method," Physica A: Statistical Mechanics and Its Applications, vol. 509, pp. 515-535, 2018.

[4] H. Goodarzi, O. A. Akbari, M. M. Sarafraz, M. M. Karchegani, M. R. Safaei, and G. A. Sheikh Shabani, "Numerical simulation of natural convection heat transfer of nanofluid with $\mathrm{Cu}$, MWCNT, and $\mathrm{Al} 2 \mathrm{O} 3$ nanoparticles in a cavity with different aspect ratios," Journal of Thermal Science and Engineering Applications, vol. 11, no. 6, article 061020, 2019.

[5] M. Goodarzi, M. R. Safaei, A. Karimipour et al., "Comparison of the finite volume and Lattice Boltzmann methods for solving natural convection heat transfer problems inside cavities and enclosures," Abstract and Applied Analysis, vol. 2014, Article ID 762184, 15 pages, 2014.
[6] M. Goodarzi, M. R. Safaei, H. F. Oztop et al., "Numerical study of entropy generation due to coupled laminar and turbulent mixed convection and thermal radiation in an enclosure filled with a semitransparent medium," The Scientific World Journal, vol. 2014, Article ID 761745, 8 pages, 2014.

[7] A. Boonloi and W. Jedsadaratanachai, "Thermohydraulic performance improvement in heat exchanger square duct inserted with $45^{\circ}$ inclined square ring," Modelling and Simulation in Engineering, vol. 2020, Article ID 3862624, 22 pages, 2020.

[8] J. E. Salhi, K. Amghar, H. Bouali, and N. Salhi, "Combined heat and mass transfer of fluid flowing through horizontal channel by turbulent forced convection," Modelling and Simulation in Engineering, vol. 2020, Article ID 1453893, 11 pages, 2020.

[9] A. Boonloi and W. Jedsadaratanachai, "Numerical study on flow and heat transfer mechanisms in the heat exchanger channel with V-orifice at various blockage ratios, gap spacing ratios, and flow directions," Modelling and Simulation in Engineering, vol. 2019, Article ID 8656435, 21 pages, 2019.

[10] M. Bahiraei, N. Mazaheri, and H. Moayedi, "Employing Vshaped ribs and nanofluid as two passive methods to improve second law characteristics of flow within a square channel: a two-phase approach," International Journal of Heat and Mass Transfer, vol. 151, article 119419, 2020.

[11] M. Bahiraei, N. Mazaheri, Y. Hosseini, and H. Moayedi, "A two-phase simulation for analyzing thermohydraulic performance of $\mathrm{Cu}$-water nanofluid within a square channel enhanced with $90^{\circ} \mathrm{V}$-shaped ribs," International Journal of Heat and Mass Transfer, vol. 145, article 118612, 2019.

[12] K. Matsubara, H. Ohta, and T. Ishino, "Direct simulation of inlet region heat transfer in a channel with repeated ribs under iso-thermal wall heating condition," International Journal of Thermal Sciences, vol. 154, article 106408, 2020.

[13] F. Li, Q. Ma, G. Xin, J. Zhang, and X. Wang, "Heat transfer and flow characteristics of microchannels with solid and porous ribs," Applied Thermal Engineering, vol. 178, article 115639, 2020.

[14] M. Bahiraei, A. Monavari, and H. Moayedi, "Second law assessment of nanofluid flow in a channel fitted with conical ribs for utilization in solar thermal applications: effect of nanoparticle shape," International Journal of Heat and Mass Transfer, vol. 151, article 119387, 2020.

[15] G. Jiang, J. Gao, X. Shi, F. Li, and L. Xu, "Flow and heat transfer characteristics of the mist/steam two-phase flow cooling the rectangular channel with column-row-ribs," International Journal of Heat and Mass Transfer, vol. 156, article 119737, 2020.

[16] W. Bai, D. Liang, W. Chen, and M. K. Chyu, "Investigation of ribs disturbed entrance effect of heat transfer and pressure drop in pin-fin array," Applied Thermal Engineering, vol. 162, article 114214, 2019.

[17] Y. Li, Y. Rao, D. Wang, P. Zhang, and X. Wu, "Heat transfer and pressure loss of turbulent flow in channels with miniature structured ribs on one wall," International Journal of Heat and Mass Transfer, vol. 131, pp. 584-593, 2019.

[18] W. Bai, W. Chen, L. Yang, and M. K. Chyu, "Numerical investigation on heat transfer and pressure drop of pin-fin array under the influence of rib turbulators induced vortices," International Journal of Heat and Mass Transfer, vol. 129, pp. 735$745,2019$.

[19] A. Boonloi and W. Jedsadaratanachai, "Numerical investigation on turbulent forced convection and heat transfer characteristic in a square channel with discrete combined V-baffle 
and V-orifice," Case Studies in Thermal Engineering, vol. 8, pp. 226-235, 2016.

[20] A. Boonloi and W. Jedsadaratanachai, "Forced convective heat transfer and thermal efficiency assessment in square channel equipped with $10^{\circ}$ wavy thin rib," Advances in Mechanical Engineering, vol. 12, no. 12, Article ID 168781402098526, 2020.

[21] Y. A. Cengel and A. J. Ghajar, Heat and Mass Transfer: Fundamentals \& Applications, Fifth edition in SI Units, McGraw-Hill Education, 2015.

[22] H. K. Versteeg and W. Malalasekera, An Introduction to Computational Fluid Dynamics; the Finite Volume Method, Second edition, Pearson Education Limited, 2007. 